\title{
Intension, Current Implementation and Improvement Path of Instructional Leadership: A school Case of Hong Kong
}

\author{
Ling Dai Yicai Zhu* \\ College of Educational Science, Tai Zhou University, Taizhou, Jiangsu, 225300, China
}

\section{ARTICLE INFO}

Article history

Received: 17 July 2021

Revised: 25 July 2021

Accepted: 15 October 2021

Published Online: 30 October 2021

\section{Keywords:}

Instructional leadership

HK primary school

Distributive leadership

Curriculum development

\begin{abstract}
This paper aims to analyze the implementation status of instructional leadership of a HK primary school that benefits in mid-ranking and mainly uses instructional leadership to develop their curriculums. Instructional leadership is the result of introducing leadership concepts into the teaching field, and it reflects the changing trend of school management to a certain extent. At present, the research on instructional leadership is limited to the principal's leadership, which limits the overall function of instructional leadership. By investigating the actuality of school and the implementation of school policies and programs, the paper deeply analyzes the existed problems in a Hong Kong school and offers optimization suggestions: strengthen the school distributive leadership construction, promote the professional development of teachers and curriculums, establish a diversified evaluation system, develop an organizational culture of democratic cooperation and improve the curriculum leadership of principals.
\end{abstract}

This paper first clarifies the development history and intension of instructional leadership, and then it sorts out the connection and difference between instructional leadership, distributive leadership and curriculum leadership. Lastly, the paper takes a Hong Kong primary school at the intermediate level as an example, analyzing the current situation and existing problems of instructional leadership mode in schools, and puts forward some suggestions to promote the development of teaching and management in schools.

\section{Literature Review}

\section{Intension and Development}

At the beginning of 1980 , the rise of the Effective

*Corresponding Author:

Yicai Zhu,

College of Educational Science, Tai Zhou University, Taizhou, Jiangsu, 225300, China;

Email: 596064720@qq.com 
Teaching Movement represented by Ronald Edmonds made instructional leadership highly valued by researchers ${ }^{[2]}$. At that time, many researchers described and analyzed the characteristics of effective schools and found that instructional leadership was an important factor affecting school effectiveness. Therefore, instructional leadership began to receive more extensive attention at both the theoretical and practical levels ${ }^{[3]}$. At that time, the teaching leader was portrayed as someone who could not only set goals, oversee processes, supervise teaching, but also create the teaching environment, solve problems, coordinate relationships, and combine expertise and personal charisma who can transform a school ${ }^{[4]}$. Ronald Edmonds, by summarizing the practical experience of school, reinforced the statement that "principals pay attention to teaching and learning" and ushered in a new era of academic research and practice of principal instructional leadership. However, excessive role expectations have not produced a large number of heroic leaders, and only a few outstanding principals who were passionate about education and competence could be expected to develop into powerful leaders ${ }^{[5]}$. To deal with this problem, in 1982, Stephen Bossert of the Far West Laboratory in San Francisco published a seminal literature review in which Stephen synthesized the findings of the literature to propose a framework for principals' instructional management behavior. The principal's personal characteristics affect the teaching management behavior, and the principal's management behavior affects the school atmosphere and the teaching and learning organization, and then affects the students' learning. The conceptual framework developed by Stephen provides a valuable perspective for subsequent scholars to use conceptualized instructional leadership in practice ${ }^{[6]}$.

In the mid-1980s, on the basis of absorbing the research results of relevant disciplines, some scholars clearly defined the intension of instructional leadership and put forward a new explanatory framework ${ }^{[7]}$. Among many definitions, the model proposed by American scholars Philip Hallinger and Joseph Murphy has the greatest influence and the highest citation rate. They define instructional leadership as the principal's leadership and management of the school's teaching work and promote the teaching of teachers and the learning behavior of students. The three core dimensions: "defining school mission", "managing curriculum and teaching" and "creating a positive school climate" were identified and finally, ten instructional leadership functions were further subdivided ${ }^{[8]}$. The management and research of principal's instructional leadership move from sampling to concrete.
Since the beginning of the 21 st century, education quality has become a strategic theme of basic education reform and development in various countries, and the learning and development of students has received extensive attention from educators and researchers. An "emerging force" is flourishing, that is, the study of instructional leadership that advocates learning as the center is constantly emerging. At this time, research on instructional leadership pays great attention to teaching and learning, and research on instructional leadership has become a global phenomenon with the appearance of learning center leadership ${ }^{[9]}$.

It can be concluded that the evolution of the intension of instructional leadership has roughly experienced the development process from the main body leadership activity to the learning-centered leadership. After summarizing various viewpoints, we define instructional leadership as the leader's influence on stakeholders such as teachers and students to effectively coordinate curriculum and teaching, so as to realize the school's teaching mission and vision and promote students' learning and development ability ${ }^{[10]}$. It is embodied in three aspects: First, instructional leadership is a kind of ability to grasp the mission of an organization that mobilizes people to fight around this mission. Second, instructional leadership refers to the leadership of a leader in the field of teaching, and it is not limited to various teaching management behaviors, abilities and performance, but also involves relevant situational factors such as organizational culture, cadre-group relationship, teacher motivation and so on. Third, instructional leadership not only leads the teaching of teachers, but also the learning of students. However, the current research on instructional leadership has not deeply explored how teachers lead students to learn, so that the effect of instructional leadership cannot be sustained for a long time, and the problems of "teaching and learning" in instructional leadership research need to be solved. Moreover, instructional leadership has developed from the traditional instructional leadership of principals to the current distributive leadership, but after all, it is led by a few people, so there are still problems in the scope and depth of its influence on teaching activities.

\section{Related Concepts}

\subsection{Curriculum Leadership}

Curriculum leadership and instructional leadership are two concepts with similar meanings ${ }^{[1]}$. Instructional leadership is inseparable from curriculum planning, design and guidance, and curriculum leadership is inseparable from monitoring, evaluation and improvement

DOI: http://dx.doi.org/10.26549/jetm.v5i2.7360 
of teaching. Instructional leaders often influence the results of curriculum and teaching by directly changing the relevant conditions, while curriculum leaders achieve the goal directly achieved by improving the ability of members in the organization. "Curriculum leadership" was put forward by famous curriculum experts such as Rambert, Grasthorne and Brubeck in the United States. It uses the theories, methods, strategies and behaviors of leadership to complete the tasks within the scope of the curriculum, to understand the curriculum, implement the curriculum, evaluate the curriculum better, and in order to achieve the fundamental goal of curriculum: improve the quality of the curriculum, promote the professional growth of teachers, develop the academic achievement of students and rebuild the school organization and culture. Sergiovanni defined CL: it provides members of the school with necessary support and resources like the basis of professional knowledge to enrich the course and teaching quality, promotes the communication between the teacher, urges schools to develop a culture of cooperation and continuous improvement, finally, achieves the target of excellence in education ${ }^{[12]}$.

Instructional leadership is a top-down leadership paradigm, which emphasizes the cooperation and control of teaching; curriculum leadership only emphasizes cooperation in teaching, the idea of sharing and the multiple sources of leadership. Instructional leaders not only emphasize the cooperation with the leader in the teaching process and the guidance of teaching activities, but also emphasize the management control of the leader ${ }^{[13]}$. While, in the teaching process, curriculum leadership only emphasizes cooperation with the leader, empowers the leader, participates in leadership, and shares power. Curriculum leadership attaches great importance to the multiple aspects of leadership, mainly because of the diversity of leading subjects. Education managers, principals and teachers at all levels can become the subject of curriculum leadership.

\subsection{Distributive Leadership}

Distributive leadership was originally put forward by the Australian social psychologist Gibb. He believed that leadership is a quality of a group and a function shared by a group ${ }^{[14]}$. In the 1990 s, distributive leadership was introduced into the research field of western educational leadership. Researchers further improved the concept and reached a consensus: leadership not only exists in some specific roles, but in the relationship between various roles in reality ${ }^{[15]}$. That is, leadership is not a personal act of the principal, but a distributed practice, which is widely distributed in the work situation of the leader. The function of distributive leadership exists in many leader interactions. The concept of instructional leadership was accepted and applied to other models like Distributed Leadership, Shared Leadership and Transformational Leadership.

Based on the view of distributive leadership, instructional leadership is a team task, which is jointly constructed by the principal, the assistant principal, the subject director, the head teacher and the course teacher. The focus of distributive leadership is to enable all professionals in the school, no matter whether they are informal management positions can participate in the practice of professional leadership. Distributive leadership pays special attention to the leading construction of senior teachers, academic leaders and teaching backbone. Compared with traditional leadership, distributive leadership attaches great importance to teamwork and advocates the construction of a good relationship between members of the organization. At the same time, it emphasizes the cooperation between informal organizations and active organizations. Through their collaboration and communication, the professional ability and cohesion of the entire educational organization are improved, and a new type of professional leadership culture is established ${ }^{[16]}$. Distributed leadership can solve the problems of insufficient personal teaching knowledge and insufficient leadership energy of principals.

\section{School Background}

The school was founded on September 1, 1989. Mr. A, chairman of Hong Kong B group, donated a large sum of money to equip and complete the school, so it was approved to take A as the school name. With "Knowledgeable, Diligence, Loyalty and Honesty" as the school motto, the school focuses on moral education, and emphasizes the balanced development of intellectual education, sports, group education and aesthetic education. The lessons are mainly given in Cantonese apart from English enhancement classes, in which all subjects are taught in English except Chinese. The school has 24 classrooms, and each grade has 4 classrooms, and the total number of teaching staff is 57 , and it is a "medium-sized" campus in HK, covering an area of about 4,000 square meters. The numbers of teaching staff and the classrooms are increasing rapidly since 2013 , but the ranking of the school is always after 200, in the mid-ranking of HK.

\subsection{Survey of the School}

School A is an aided school. In Hong Kong, aided schools are a non-profit-making advocacy group that 
receives government funding to provide free education. The education fee is largely funded by the government, but its management is the responsibility of the school council. There are 423 such primary schools in Hong Kong, accounting for about 81 percent of the total. The management of the school is delegated to the Council by the sponsoring body. Its curriculum and enrollment are basically the same as that of a government primary school. Students are comprised of local students, cross-boundary students and NCS. The school sets English classes, English enhancement classes and Chinese classes. For the English class, all subjects are taught in English except the Chinese course. There are two subject panels for Chinese, English \& Mathematics.

After the semi-structured interviews and investigations, school A provides quality education by establishing a school executive committee above the school administration. The members include a principal, parent representatives, teacher representatives, teacher managers and senior teachers. The committee directly reports to the Board of Directors in order to ensure effective decision making, management and efficient support. The committee is formed by the following teams: the teaching and learning team, the school-culture and student support team and the development team. Each team will propose a designed and revised policy (see Figure 1).

\subsection{Current Implementation of Instructional Leadership}

This aided elementary school uses typical instructional leaders. The school management committee has set up a three-year main focus for the Teaching \& Learning group to optimize Teaching \& Learning strategies and strengthen students' autonomous learning skills and abilities. And teaching and learning group sets the strategy plans according to the Major Concerns which is set by the School Administrative Committee: 1. Designing some activities to enhance student self-directed learning skills; 2. Creating workshops to introduce the ways to simulate student reading skills; 3 . Developing some strategies to intensify student in doing the e-assignments; 4. Promoting STEAM in each subject; Also, the mathematics panels have designed different activities to fulfill the strategy plans which are set by T\&L group. The committee is also responsible for the management of courses and teaching. They produce teacher manuals to correct students' work, design assessments, and recommend time allocation for each lesson. All the worksheets, assessment papers, lesson plans and student works will be saved in school cloud servers. Each subject group holds regular meetings, and each meeting is attended by the principal and assigns tasks. A teacher in the school said that they had the meeting about 1 or 2 days during the peak season, and

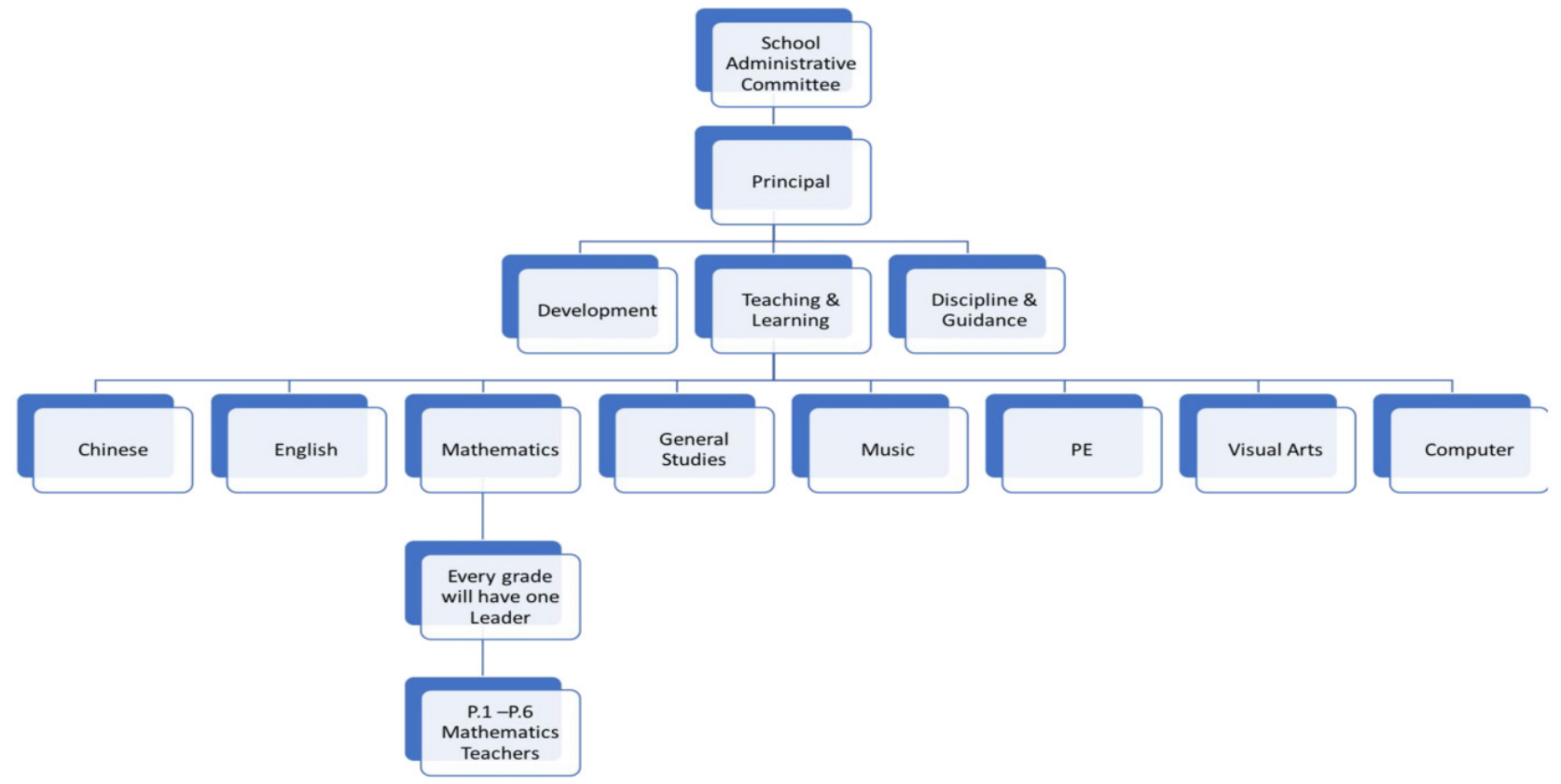

Figure 1. Administrative combination: 
they often needed to analyze the content of the meeting and get many missions from each meeting. Regarding the supervision of teaching arrangements, members of the organizing committee will conduct random checks on each class and conduct class observations to promote the development and ranking of teachers. They also evaluate teachers by monitoring students' work and analyzing and recording students' evaluation performance. This can enhance the scheme to improve the assessment performance. Teachers in school A are also required to do a lot of work to promote the teaching atmosphere, such as teachers designing activities that simulate students' autonomous learning. Teachers use Geogebra and NearPod Apps to write math programs, and use different levels of worksheets to increase learning diversity in the class, and teachers have common planning time every week. School A provides workshops to enhance teachers' teaching skills. In addition, students can get different support schemes from the universities of HK and EDB.

\section{Analysis of the School}

\subsection{The Reason Why School Mainly Uses the Instructional Leadership}

Curriculum leadership of principals is a key factor influencing curriculum reform and practice. As a ranked school, a person with rich experience and prestige to lead the school out of the bottleneck is of great significance to the school. Most of the staff in the school only have a master degree, and there are not many veteran teachers who can be competent for important positions. Therefore, Ms. C, who has many years of experience as a principal, was elected as the leader of the school.

\subsection{The Weakness of the Instructional Leadership of This School}

As the administrative structure setting, the school should have a good schema of distributive leadership. However, the school pays too much attention to instructional leadership, and teachers cannot have much decision-making power. In fact, the principal's decision may not be completely suitable for front-line teaching, and it will often deviate from ideals and reality.

One teacher in this school said that they often need to work very late because of too much impractical mission from the principal. That's the corrupt practice of highly instructional leadership.

After the investigations, researcher found that there are many other problems exposed in the assessment and supervising aspect. The supervising system is imperfect, principals and committee only have time to observe several classes, assessment of learning and teaching is the direct way for teachers to get feedback and improve themselves. They do not involve subject differences. They only use the same set of class assessment forms to evaluate various subjects such as mathematics and English. This makes teachers only adopt similar teaching designs and rarely carry out creative teaching, which can not only improve children's learning interest, but also fully consider the children's learning psychological characteristics. These weaknesses make it impossible for all subjects to develop rapidly.

\section{Improvement Path of Instructional Leadership}

Strengthen the construction of distributive leadership while the school should give more rights and space for teachers. We believe that the role of teachers as leaders should be strengthened in the teacher role series, that is, teachers are leaders ${ }^{[17]}$. The point of "teacher is a leader" is put forward because the characteristics of the teacher's leadership are in line with the teaching practice of its role, and the teaching activities are highly similar to the leadership activities. Taking teachers as the leading role can improve teachers' teaching leadership ability and promote the transformation of teachers' concepts. It has important value and significance in teaching practice.

In addition, diversified classroom assessments can help teachers better understand the highlights and deficiencies of the classroom. Classroom learning is the main way for students to achieve their learning goals. Teachers are advised to use a variety of assessment methods and interacted with students. Teachers should pay attention to individual differences of students and mobilize students' enthusiasm, initiative and interest in learning. The purpose of the assessment is to promote learning. With the diversification of the education system reform and the need for diversifying talents in the development era, the teaching model has become more and more important. At the same time, a well-functioning classroom evaluation system is increasingly closely related to the achievements of teachers and students. Effective teachers, classrooms, and student assessment systems can truly assess the goals of teaching and learning.

Lastly, develop an organizational culture of democratic cooperation. Leaders should have democratic concepts and styles of work, and principals' role should change from commanding to cooperating with teachers. It is necessary for leaders to create an atmosphere of collaboration and sharing in schools. Principals should let teachers and students participate in instructional leadership work through collective activities and empowerment, stimulate teachers' team consciousness, and realize the common growth of both individuals and organizations. Besides, 
exploring university-government-school cooperation is also a valuable way to benefit teaching leadership.

In addition, find scientific and appropriate implementation approaches to improve the curriculum leadership of principals. As the principal, he should make the school's school-running philosophy a code of conduct acceptable to every member of the school, listen to teachers' voices on curriculum construction, do more communication and share more, and grasp the direction of curriculum reform. As the principal, he should accurately construct the structure of all kinds of courses, attach importance to the teaching values in the course of implementation, be good at summarizing all useful and effective methods, and promote the curriculum construction to support the characteristic development of the school strongly. As the principal, he should pay attention to cultivating excellent teachers, be good at discovering leading figures in the teaching team, create favorable conditions, build a teacher growth platform, and improve the professional level of teachers, to ensure the quality of curriculum construction. The curriculum and the teaching are inseparable and consistent. All the policies and the strategies should keep their integrality and relevance. Becoming an excellent school to obtain student success, it is very necessary for school leaders to have outstanding experience, knowledge and skills in curriculum setting and teaching leadership.

\section{Funding}

Taizhou University First-class Undergraduate Major Construction Point "Primary Education" Stage Research Achievements (Project No. 20YLZYB03).

The Project of Philosophy and Social Science Research in Colleges and Universities in Jiangsu Province: Research on the Construction of Teacher Education Ideological and Political Discourse System from The Perspective of Student. Project no. :(2021SJA2158).

\section{References}

[1] Bush, T. \& Glover, D. (2014) School leadership models: what do we know? School Leadership \& Management, 34(5), 553-571.

[2] Ronald Edmonds. (1981). The last obstacle to equity in education: Social class. Theory Into Practice (4).

[3] Decheng Zhao. (2013). Teaching Leadership: Connotative Assessment and Future Research Directions. Foreign Education Research (04),96-103. (in Chinese)

[4] Min Wang, Yongxin Zhu. (2020). The progress and prospect of teacher leadership research. Education Science in China (Chinese \& English) (04),130-143. (in Chinese)
[5] Halinger P.Leading educational change:Reflections on the practice of instructional and transformational leadership. Cambridge Journal of Education, 2003 (3):329-352.

[6] Dingrong $\mathrm{Hu}$, Fangping Qi. (2021). Research on Teaching Leadership: Historical Evolution, Real Dilemma and Future Trend. Modern Educational Management. (in Chinese)

[7] Hallinger, P., and R. H. Heck. 1998. "Exploring the Principal's Contribution to School Effectiveness: 1980-1995." School Effectiveness and School Improvement 9 (2): 157-191.

[8] Hallinger, P., Murphy, J.. Assessing the instructional leadership behavior of princi- pals[J]. Elementary School Journal, 1985, 86(2): 217-248.

[9] Dingrong Hu, Fangping Qi. (2021). Research on Teaching Leadership: Historical Evolution, Real Dilemma and Future Trend. Modern Educational Management. (in Chinese)

[10] Decheng Zhao. (2013). Teaching Leadership: Connotative Assessment and Future Research Directions. Foreign Education Research (04),96-103. (in Chinese)

[11] Daming Feng. The Resurgence and Logical Turn of Teaching Leadership Research in the West. Education Research, 2012(3):135-139. (in Chinese)

[12] Ahtiainen Raisa, Sulonen H. (2021). Finnish early childhood education and care leaders' perceptions of pedagogical leadership and assessment of the implementation of the National Core Curriculum in times of change. Australasian Journal of Early Childhood(2).

[13] Edmond Hau-Fai Law, Maurice Galton, Sally WaiYan Wan.(2007).Developing Curriculum Leadership in Schools: Hong Kong perspectives. Asia-Pacific Journal of Teacher Education (2).

[14] Gibb, C. Leadership[A]. G. Lindzey. Handbook of Social Psychology[C]. MA:Addison-Wesley, 1954. 877-917. from Leithwood, K. et al. Second International Handbook of Educational Leadership and Administration[M]. Dordrecht:Kluwer Academic Publishers, 2002.655.

[15] Ogawa, R. T. , and Bossert, S. Leadership as an Organizational Quality. Educational Administration Quarterly, 1995 (2).

[16] Xi Zhang. (2017). Organizational Construction of Teaching Development of University Teachers from the Perspective of Distributed Leadership. College Education Management (05),102-109. (in Chinese)

[17] Tsui, K.T. (2014). Curriculum leadership developments: Lessons learned and achievements made. In C. Marsh, \& J. C. Lee (Eds.), Asia's high performing education systems: The case of Hong Kong. London: Routledge. 